\title{
Artículos
}

\section{Análisis comparado de procesos de descentralización urbana: los casos de Barcelona y Buenos Aires}

\section{Comparative analysis of urban decentralization processes: The cases of Barcelona and Buenos Aires}

Giselle González*

\section{Resumen}

En este artículo se describen y comparan politicas públicas de territorialización de Buenos Aires y Barcelona. Desde un diseño cualitativo, el trabajo se aproxima a experiencias en las que se observan procesos de consolidación de políticas públicas de regionalización territorial, analizando especialmente el proceso de consolidación y las problemáticas que presentan en la actualidad. La investigación se aborda desde tres ejes especificos: las condiciones del contexto, las políticas y los actores. Desde alli se indagan las relaciones de poder entre los diferentes actores, el modo en que se constituyen los actores politicos y los grados de influencia en los procesos de toma de decisiones en cada ciudad. De tal comparación se evidencia que las iniciativas en Buenos Aires se diseñan desde lógicas multinivel, pero su implementación muestra fuertes rasgos de centralización en el poder central; mientras que en el caso de Barcelona, se plasman diseños multinivel y una distribución de poder reticular que la acerca a un modelo cooperativo de gobernanza metropolitana.

* Universidad Nacional de la Plata, Facultad de Humanidades y Ciencias de la Educación, Instituto de Investigaciones en Humanidades y Ciencias Sociales. Dirección: Calle 51 e/ 124 y 125, s/n, Buenos Aires, Argentina. Correo: gonzalez giselleu@gmail.com ORCID: https://orcid.org/0000-0001-5818-0735 
Palabras clave: gobernanza urbana; territorio metropolitano; regionalización; descentralización.

\begin{abstract}
Public territorialization policies between Buenos Aires and Barcelona are described and compared. From a qualitative design, the work is close to experiences in which processes of consolidation of public policies of territorial regionalization are observed, especially analyzing the consolidation process and the problems they currently present. The research is approached from three specific axes: context conditions, policies and actors. From there the power relations between different actors are investigated, the way in which political actors are constituted and the degrees of influence in the decision-making processes in each city. From the comparison it appears that the initiatives in Buenos Aires are designed from multilevel logics but their implementation shows strong centralization features in the central power. While in the case of Barcelona, multilevel designs and a distribution of reticular power that brings it closer to a cooperative model of metropolitan governance are embodied.
\end{abstract}

Keywords: urban governance; metropolitan territory; regionalization; decentralization.

\title{
Introducción
}

Las cifras sobre el desarrollo de las ciudades de la Organización de Naciones Unidas (ONU) se exponen anualmente. En 2016 se constató un indicador histórico: el carácter urbano de la mayoría de la población del planeta $(54.5 \%)$. Si la dinámica persiste, los habitantes de las ciudades pueden llegar al $70 \%$ de la población mundial en 2050; esto es, en menos de cien años incrementarán su presencia de un tercio a dos tercios de la humanidad, un proceso inédito. Pero estas cifras reflejan cuestiones más allá de la demografía: a) en las 500 ciudades más dinámicas del mundo vive el $23 \%$ de la población, pero se genera el 60\% del PIB del planeta; $b$ ) el financiamiento del capitalismo global tiene uno de sus grandes anclajes en las rentas ur- 
banas; c) el índice de Gini (distribución desigual de los ingresos) ha crecido en las metrópolis $20 \%$ en el transcurso de veinte años, con su correlato de segregación residencial.

En América Latina, el peso demográfico de las ciudades ha pasado del 25 al 75\% en un siglo; en el mismo periodo el PIB urbano ha llegado del 20 al $80 \%$ del total. De las 25 megalópolis del mundo (más de 10 millones de habitantes), cuatro son latinoamericanas. Se trata de metrópolis desiguales y segregadas con niveles elevados de informalidad laboral; poseen economías metropolitanas dinámicas, pero ineficientes; tienen procesos de urbanización extensiva, así como altos índices de congestión y contaminación.

Aparecen también en las ciudades lógicas de acción colectiva y otras alternativas innovadoras: prácticas urbanas transformadoras, dinámicas de ampliación democrática, empoderamiento social y reconexión de las instituciones del bien común. Se articulan redes de un nuevo municipalismo internacional, espacios de acción y aprendizajes cruzados para avanzar hacia el derecho a la metrópoli. La vieja política parece agotar sus capacidades de procesar las transformaciones y crecen nuevos movimientos que emergen desde la proximidad. El derecho a la ciudad aparece como una dimensión cotidiana del conjunto de los derechos sociales, culturales y económicos. Comienza a trazarse un acercamiento a la esfera local, una apuesta para poner la vida en manos de la gente, crear capacidades de autogestión y forjar soberanías municipales.

La arquitectura del municipalismo internacional es incipiente y dinámica, con una agenda de actuación aún en formación. En la Unión Europea, las ciudades como Londres, París, Berlín o Ámsterdam son hoy referencia de modelos de convivencia multicultural, gestión pública del agua, control de alquileres y políticas de transición socioecológica. Allí, las redes de "ciudades refugio" emergen frente al fracaso de las políticas de la Unión Europea para contener la crisis de los refugiados. Ante la lógica de levantamiento de muros $\mathrm{y}$ cierre de fronteras, en los municipios se ponen en marcha programas de acogida.

En Estados Unidos la red de ciudades de derechos humanos convierte a éstas en puestos de seguridad residencial frente al racismo de estado. En América Latina se activa un ciclo de nuevos munici- 
palismos con candidaturas ciudadanas, presupuestos participativos y autogestión comunitaria (Valparaíso, Rosario, Montevideo, Belo Horizonte, etc.). A escala global, el C-40 se configura como la red de metrópolis que lidera las políticas de protección y justicia climática bajo el paraguas del Acuerdo de París, construyendo capacidades de gobierno urbano sin precedentes. Destaca la presencia activa y el impulso a CGLU (Ciudades y Gobiernos Locales Unidos) y a eurociudades, las dos apuestas más avanzadas del protagonismo de las urbes en escenarios de gobernanza multinivel: la presencia directa en la agenda urbana de Naciones Unidas y en las políticas públicas de la Unión Europea, respectivamente.

La configuración de espacios híbridos, con gobiernos locales y movimientos urbanos, sitúa el derecho a la ciudad como terreno compartido donde se van tejiendo alianzas público- comunitarias. En los últimos años se ha intensificado la creación de programas específicos en varios continentes para sostener financieramente esta cooperación. Por otro lado, las urbes han creado redes de solidaridad y apoyo a las ciudades en zonas de conflicto o de desastres naturales. Subirats (2016) abona a esta visión definiendo que es en las ciudades y en la escala territorial más cercana donde hoy se perciben los procesos y efectos de la globalización y la europeización, y es también en este escenario en el que la proximidad emerge como poder capaz de articular soluciones adecuadas a los problemas concretos y reales de la ciudadanía.

La realidad no es estable, dada y universal, sino localizada, histórica y cultural. Por lo tanto, es múltiple. La multiplicidad implica realidades que están, necesariamente, ausentes, que son alteridad. En ese sentido, el objeto de una política pública, sea todo un barrio o una plaza concreta, puede concebirse como objeto múltiple y cambiante, no como una realidad dada y universal. Las ciudades se construyen como espacios sociales a partir de la participación de sus actores territorialmente situados. Pero depende y se entiende también a partir de lo que no cabe, de lo que no se aborda, de lo que no es movilizado ni incorporado (Grau-Solés, Iñiguez-Rueda y Subirats, 2011). 


\section{Conceptualización teórico-metodológica}

El punto de partida del análisis es el modelo de redes de política ( $g o-$ vernance) (Lowndes, 2005; Stoker, 2004; Brugué, 2002); en particular, la perspectiva de la gobernanza urbana, que problematiza las coordenadas espaciales propuestas por la gobernanza y la calidad de las intervenciones en democracia de esas redes (antes que la eficiencia). Es decir, no todos los actores de esas redes pueden considerarse protagonistas políticos dado que no hay poder equivalente en sus intercambios (Blanco, 2009; Dalton, 2004; Grau-Solés, Iñiguez-Rueda y Subirats, 2011).

La literatura sobre gobernanza tiende a presentar a las redes como un paradigma de política emergente

[...] enmarcado dentro de un conjunto más amplio de cambios en la economía y la sociedad, que se han titulado de diversas maneras como posmodernidad, postindustrialismo o postdivismo [Stoker, 2004, p. 9].

Esto implica que tales transformaciones socioeconómicas han allanado el camino para una "crisis" en el gobierno burocrático tradicional, y para el surgimiento de nuevas formas de regular los conflictos sociales.

Si bien el modelo de governance incorpora el ciclo de políticas, lo hace más dinámico y cooperativo, considerando que las etapas de una política pueden darse sin un orden prescrito. La gobernanza urbana, en cambio, sitúa la productividad de la política en las ciudades, donde se concentra la mayor complejidad y diversidad de relaciones sociales, y no toma en cuenta a la gobernanza como principio universal que se puede aplicar a cualquier espacio.

La gobernanza urbana podría entenderse como la respuesta europea, marxista y comunitarista a la perspectiva originalmente norteamericana de governance, de intención prescriptiva y universal. En este sentido, la gobernanza urbana recorre una línea de derecha a izquierda en la que se sitúan diferentes autores para intentar explicar modelos de gobernanza en la ciudad. Esto es, ya no se plantea la gobernanza como principio general aplicable a cualquier escala, sino que se utiliza para abordar lo que sucede estrictamente en los espa- 
cios urbanos donde se concentran diferentes intereses en pugna. Desde este punto de vista, existen diferentes posiciones acerca del modo en que se construye la política pública a nivel regional y/o local.

Algunos autores se refieren a la emergencia de una "gobernanza empresarial urbana" basada en el intercambio, en la cooperación entre las elites institucionales y empresariales a favor de ciertas concepciones de desarrollo económico, asociada a la reestructuración de las políticas sociales y a la privatización de los servicios urbanos (Harding, 1995).

Otros autores han advertido de los riesgos democráticos que comporta la emergencia de un nuevo paradigma de gobernanza urbana, donde la representatividad de las élites participantes puede ser escasa, las reglas de juego confusas y las líneas de responsabilidad indefinidas. En parte, este tipo de lecturas del cambio político urbano conectan con aproximaciones teóricas estadounidenses como las de las "máquinas de crecimiento" (growth machines) o la teoría de los "regímenes urbanos" (urban regimes) (Stone, 1989), las cuales coinciden en remarcar las dinámicas de cooperación entre élites urbanas, públicas y privadas para la promoción de la competitividad económica de las ciudades.

En el otro extremo, es posible identificar redes de gobernanza permeables, más plurales internamente, inclusivas con respecto a los colectivos menos organizados o desfavorecidos, transparentes y participativas. Modelos que parecen aproximarse a patrones de gobernanza participativa y proximidad, con nuevas oportunidades para la participación directa de la ciudadanía (Newman, 2005; Denters y Rose, 2005). Tales oportunidades para la participación ciudadana son mayores cuando las redes de gobernanza se articulan en los ámbitos territoriales de proximidad, tal y como ocurre con las redes para la regeneración de espacios desfavorecidos.

Desde estas perspectivas cobra relevancia la doble distinción sobre la política y las políticas, desarrollada en los modelos tradicionales de Lowi (1972) y Williamson (1979) (citados en Subirats, 2016). Contrariamente a la tradicional línea que va desde la política (politics) a las políticas (policies), algunas experiencias recientes dan cuenta que las políticas definen el tipo de política, es decir, policies determina politics. Normalmente se piensa que, dependiendo de 
la orientación política de los gobiernos y de los partidos, las políticas acabarán siendo de derecha o de izquierda, más transformadoras, menos transformadoras; es decir, la ecuación sería politics influye en policies, o la política determina a las políticas. En un trabajo reciente, Subirats (2016) plantea que lo que Lowi trató de demostrar es que, en muchos casos, la forma concreta que tienen las políticas y el ámbito sectorial en el que se desarrollan acaban definiendo el tipo de conflicto político. De esta manera, se puede invertir la ecuación y afirmar que son las políticas las que definen el tipo de política, o en inglés, policies determina politics.

Desde la perspectiva del territorio, la autoridad y los derechos, esta transformación adopta la forma de un reensamblaje de espacios en el marco de modelos multinivel donde operan las escalas subnacional (local o regional), nacional y global. Aunque desde una teoría crítica (Lefebvre, 2013; Brenner, 2017), estos espacios se constituyen como resultado de los productos sociales y, desde este punto de vista, se trata de espacios sujetos a desarrollos desiguales.

El espacio es el resultado de la acción social, las prácticas, las relaciones, las experiencias sociales, pero a su vez es parte de ellas. No hay relaciones sociales sin espacio, de igual modo que no hay espacio sin relaciones sociales.

Durante largo tiempo se ha tenido por costumbre presentar el espacio como un receptáculo vacío e inerte que sólo posteriormente sería ocupado por cuerpos y objetos. Para Lefebvre (2013), esta orientación responde a una razón ideológica para imponer determinada visión de la realidad social y del propio espacio, y determinadas relaciones de poder. Una ilusión que rechaza que el espacio sea un producto social. De este modo, el espacio ya no constituiría un elemento objetivo, neutral, inmutable y definitivo.

En particular, el espacio público habilita reglas para construir

[...] desde un proceso colectivo protagonizado por agentes sociales $\mathrm{y} / \mathrm{o}$ institucionales que buscan generar valor público a través de la generación de nuevas ideas, servicios y relaciones [Cruz y Blanco, 2018, p. 129]. 
No obstante, la literatura sobre gobernanza que más y mejor ha canalizado la emergencia de nuevas formas de hacer política en distintos países se ha centrado en aspectos estructurales, causales y explicativos; mientras que la comparación sobre las desiguales trayectorias de cambio según los territorios locales o los distintos sectores de política pública en un mismo contexto territorial han sido escasamente explorados.

\section{Objetivos e hipótesis de trabajo}

Este artículo examina de qué manera se han plasmado algunas experiencias de regionalización territorial desde una perspectiva que involucra la comparación entre dos ciudades: Buenos Aires y Barcelona. La indagación se hace operativa al explorar tres dimensiones específicas: a) las condiciones jurídico institucionales, b) las políticas territoriales, y c) los actores. Es en la intersección de estas tres dimensiones donde se constituyen las relaciones de poder entre los actores situados en los diferentes niveles de gobierno. Su tratamiento abre un conjunto de preguntas que permiten orientar el análisis: ¿cuáles son las condiciones de contexto en cada ciudad?, ¿qué actores participan efectivamente de las experiencias territoriales?, ¿cómo se toman las decisiones?, ¿cuáles son las estrategias políticas que desarrollan los actores que ocupan el centro y cuáles las de las periferias más significativas?, ¿las relaciones son de cooperación o competición?, ¿hay sintonía o disparidad?, ¿de qué manera se manifiestan esas expresiones?

Las ciudades seleccionadas representan un terreno empíricamente fértil para abordar estas preguntas y contrastar los elementos teóricos involucrados en relación con las dinámicas de cambio en las políticas públicas urbanas.

En el caso de Buenos Aires se toman experiencias de regionalización de la educación superior para las cuales se ha colectado información en una investigación previa (González, 2013). Para Barcelona, se analizan iniciativas de descentralización territorial plasmadas en algunas políticas de innovación social y gobernanza urbana recientes. Para la selección de los casos se tomó en cuenta 
la centralidad de cada una de las ciudades en términos de evolución metropolitana, autonomía institucional y proyección internacional.

La hipótesis que orienta el estudio afirma que los procesos de descentralización metropolitana han inducido cambios a nivel internacional a partir de modelos isomórficos de gobernanza multinivel. Esto es, bajo un mismo modelo conceptual se han aplicado políticas de gobernanza en redes a diferentes países occidentales y latinoamericanos. Pero estas políticas globales han recibido respuestas locales heterogéneas. La brecha entre un diseño global y los desempeños locales parece obedecer a dinámicas sociales mucho más complejas asociadas a específicas configuraciones políticas, culturales y organizacionales de las ciudades bajo análisis.

El diseño del estudio es cualitativo y se basa en el análisis de fuentes documentales y en un registro de observación no participante en ambas ciudades. Para el caso de Buenos Aires se seleccionó un área temática donde la regionalización ha sido frecuente: el campo educativo. Mientras que en Barcelona se analizaron experiencias de descentralización regional distintivas por su impacto exitoso en términos de involucramiento de los actores territoriales: la innovación política y social.

En las secciones subsiguientes se presentan, en primer lugar, los resultados registrados para cada uno de los casos. Luego, una discusión de sus aspectos comunes y divergencias. Al final se incluyen unas breves conclusiones.

\section{El caso de Buenos Aires}

\section{La política y las condiciones institucionales}

Buenos Aires es la ciudad capital de Argentina. Su centralidad territorial respecto del conjunto del territorio federal tiene sus orígenes en el Virreinato del Río de La Plata, ya que en ese lugar se establecieron las autoridades monárquicas y desde allí cobró relevancia la actividad comercial de la región metropolitana, por su cercanía al puerto, sumado a que Buenos Aires se había constituido como el principal escenario sociopolítico desde los inicios de la colonización española. 
En este sentido, desde muy temprana edad, Buenos Aires asumió un elevado dinamismo urbano y territorial.

La Constitución Nacional $(\mathrm{CN})$ es la norma máxima que regula el ordenamiento territorial. Cuando hablamos de constitución nos referimos al principio de organización que permite identificar aquello en lo que consiste el Estado como unidad política. En un sentido total, el Estado no tiene una constitución, sino es una constitución, formada por tres segmentos o estructuras, a saber: la costumbre constitucional, que se expresa en la conducta de un pueblo o en la práctica de los órganos de gobierno; la ideología constitucional, que constituye el sentido común social o el "espíritu del pueblo", hecho de valores sociales; y la normativa constitucional, resultado de la lucha histórica que se encarna en la constitución positiva del Estado.

En el federalismo argentino las provincias son unidades políticas iguales (cada una está representada por tres senadores en el Congreso); son unidades indestructibles porque los poderes constituidos nacionales no pueden modificar su autonomía (no se puede federalizar una provincia, pero sí municipalizarla). El federalismo argentino se crea a semejanza de los estados independientes de Estados Unidos. En Argentina, las provincias son autónomas porque ellas "se dan sus propias instituciones locales y se rigen por ellas" (art. 122, CN). "Cada provincia dicta su propia constitución conforme a lo dispuesto por el artículo $5[\ldots]$ ” (art. 123, CN).

Las provincias argentinas no tienen derecho de secesión (es decir, de separarse por decisión propia) ni de nulificación (es decir, nulificar el derecho federal que dicta el Congreso por propia decisión), como sí ocurre en las confederaciones.

Como poderes propios y exclusivos, las provincias tienen el dominio originario de los recursos naturales existentes en su territorio (art. 124), lo cual implica que ellas pueden controlar que la legislación del Congreso sobre dichos recursos no las afecten patrimonialmente (en tal sentido, podrán pedir control de razonabilidad por parte de los jueces) y también podrán intervenir en las concesiones de dichos recursos si no estuvieren concesionados o si hubieren vencido las otorgadas por la Nación.

Entre las potestades propias que les confiere la Constitución a las provincias está la de integrar un organismo fiscal federal para contro- 
lar y fiscalizar la ejecución de la coparticipación impositiva federal (inc. 2 del 75).

"Las provincias conservan todo el poder no delegado por esta Constitución al gobierno federal" (art. 121), es decir, ejercen el poder de reglamentar las leyes nacionales y los derechos constitucionales en la medida en que las leyes y los derechos deban ser aplicados en sus territorios. Tienen plena potestad legislativa en materia de administración provincial.

Ellas "conservan [...] el poder que expresamente se hayan reservado por pactos especiales al tiempo de su incorporación" (art. 121), como lo hizo la Provincia de Buenos Aires en 1859, en el Pacto de San José de Flores, con motivo de su incorporación a la unidad nacional (se reservó poderes especiales sobre el Banco de la Provincia y sobre la navegación en el Río de la Plata).

Al conservar las provincias el poder no delegado a la nación, ellas teóricamente tienen más poderes que esta última porque lo no delegado, al no ser taxativo, será siempre mayor que lo expresamente enumerado como potestades nacionales. Aunque los hechos no parecen confirmar la teoría.

Tienen poderes concurrentes con la nación, según las atribuciones que en tal sentido les reconoce a ambos la Constitución; promover su industria, la inmigración, la construcción de ferrocarriles y canales navegables, etc. (artículo 75, CN, y artículo 125 sobre potestamiento a provincias).

También existen atribuciones concurrentes entre la nación y las provincias en materia tributaria, pero solamente en el supuesto de que una provincia no se adhiriera al pacto fiscal.

Pueden crear regiones para el desarrollo económico y social, así como establecer órganos con facultades para el cumplimiento de sus fines (artículo 124). La regionalización que ha sido incluida por la reforma de 1994 no implica una modificación de la prohibición histórica de que las provincias celebren tratados parciales de carácter político (dicha prohibición subsiste en el art. 126). No se trata de regionalizar la política del país, sino solamente su economía en pos de un mejor desarrollo económico y social. Es por ello que a la hora en que las provincias se dispongan a firmar tratados parciales de carácter regional, éstos deben apuntar a crear polos de desarrollo: comités 
de cuencas hídricas, ciudades científicas o emprendimientos conjuntos con un objetivo de esa naturaleza.

Pueden celebrar convenios internacionales en tanto no sean incompatibles con la política exterior de la nación y no afecten las facultades delegadas al gobierno federal o al crédito público del país, con conocimiento del Congreso Nacional (art. 124).

Si bien las áreas objeto de federalización son escasas en el campo de las políticas educativas, se evidencian algunas iniciativas relevantes, pues allí se han creado políticas de regionalización. Un ejemplo de ello es el Consejo Federal de Educación en tanto organismo de concertación, acuerdo y coordinación de la política educativa nacional. Otro antecedente relevante lo constituye el Plan Taquini de regionalización de universidades argentinas, de 1968, cuando se dispuso la creación de un sistema que tuviera al menos una universidad por provincia.

En este marco, el plan de regionalización de la educación superior de 1995 es un caso ilustrativo del modo en que se han desarrollado diferentes procesos de regionalización en el campo educativo. A continuación, se expone de qué manera se ha desarrollado dicha experiencia, quién la impulsó, cómo han sido sus dinámicas, y quiénes participaron.

\section{Las políticas territoriales}

En 1995, en el marco de la Ley 24.521 de Educación Superior se crearon siete Consejos de Planificación Regional de la Educación Superior (CPRES). Dichos CPRES expresan la organización de regiones educativas (Noroeste, Noreste, Centro, Metropolitana, Bonaerense, Nuevo Cuyo y Sur) para potenciar su desarrollo, acorde a las demandas relevantes de cada región y a sus capacidades físicas y potenciales.

El CPRES se piensa como un instrumento de política activa a cargo del estado nacional. Su origen puede entenderse en el marco de un proceso de políticas orientadas al mejoramiento del sistema de educación superior y a la adecuación de sus programas académicos y científicos. Surgió a partir de la Ley 24521/95, luego de un proceso 
de fuertes debates en torno a la forma de concebir el sistema de enseñanza superior en Argentina. La Ley permite visualizar al CPRES como el arreglo institucional que surge de la transacción entre dos perspectivas políticas: una autonomista y otra de mayor regulacionismo estatal. En este ámbito del debate se comprende la incorporación del CPRES como un instrumento de política pública, generando espacios para una mayor regulación ministerial en el sistema de educación superior; aunque en el nivel institucional se profundizara la autonomía de las universidades nacionales en su aspecto económico, autorizándolas a cobrar tasas y servicios de capacitación y extensión universitaria (garantizando lo intangible de esos ingresos), a establecer los salarios del personal docente y no docente, y facultándolas para dictar normas restrictivas al ingreso. Entonces, el CPRES tiene el propósito inicial de generar espacios de planificación, pero en un marco autonómico de laissez faire.

El diseño institucional que instituye al CPRES encarna el espíritu general de la Ley 24521/95, caracterizada por un enfoque de planificación descentralizada y regional, con alto nivel de autorregulación del sistema.

La configuración regional del CPRES parece, en parte, ser tributaria del paradigma de planificación de los años sesenta: el Noroeste Argentino (NOA), el Noreste Argentino (NEA) y la Patagonia. Pero resulta heterodoxa a esa tradición el armado de los CPRES Centro Oeste (COES) y Centro Este (CEE), cuando tradicionalmente las regiones fueron Cuyo, Centro y Mesopotamia.

La Ley 24.521 de 1995 no detalla qué funciones concretas debía cumplir el CPRES en los hechos, pues éstas se fueron definiendo tanto en la composición como en la dinámica organizacional de la institución. Sus actores fueron imprimiendo, en su intervención, de qué manera participaría el CPRES en la política pública y universitaria. Entre 1996 y 2007 se delineó un esquema normativo impulsado por distintas demandas de tres grupos de actores predominantes: el gobierno nacional, las autoridades ministeriales y los órganos de gobierno colegiado del campo universitario (el Consejo Interuniversitario Nacional - CIN-, que concentra a los rectores de universidades público-estatales y privadas, y el Consejo de Universidades -CU-, donde sólo se agrupan las universidades públicas y estatales). Estas 
iniciativas dieron lugar a un sistema jurídico con tres tipos de normas: a) dos decretos del Poder Ejecutivo Nacional (PEN) conforme a lo dispuesto por el artículo 99, inciso 2, de la Constitución Nacional: el Decreto 576/96 derogado en 1999, y el Decreto 1047/99 (síntesis de dos decretos derogados en 1999: el 576/96 y el 2282/93); b) cuatro resoluciones ministeriales (RM): 602/95, 200/96, 1671/06 y $1180 / 07$; y c) los apoyos inducidos por seis acuerdos plenarios (AP) del CIN. Dicho marco normativo ha sido y es susceptible de múltiples interpretaciones según la posición de poder que ocupe cada uno de los actores. Esto ha dado lugar a problemas de implementación en cada una de las regiones.

\section{Los actores}

El diseño institucional del CPRES habilita un espacio legal para la reunión de diversos actores en un mismo espacio de negociación. Según indica la normativa vigente, el CPRES funciona a partir de la representación y actividad desempeñada por los actores que lo componen. Éstos se sitúan en distintos niveles de gobierno y pertenecen a ámbitos de gestión pública y privada.

La investigación permite dar cuenta de tres tipos de actores: estatales, paraestatales y sociales. Los estatales están representados por el estado nacional (el Ministerio de Educación de la Nación a través de la Secretaría de Políticas Universitarias) y los niveles subnacionales de gobierno: las autoridades de jurisdicciones provinciales y municipios.

Los paraestatales involucran a:

[...] todas las autoridades académicas, estatales y no estatales, dado que todas (de diversa manera los de las instituciones "públicas" y los de las "privadas") se diferencian del funcionario público típico, pero todas, al mismo tiempo, sufren restricciones, obligaciones impuestas por el Estado y un control estatal, que no permite confundirlos con actores sociales que, típicamente, actúan con un mayor grado de autonomía con respecto al Estado [Potenza dal Masetto, en González, 2011]. 
En esta categoría se ubica al Consejo Interuniversitario Nacional (CIN), al Consejo de Universidades (CU) y al Consejo de Rectores de Universidades Privadas (CRUP).

El grupo de actores sociales está integrado por universidades de gestión pública y privada que pertenecen a cada una de las regiones, y también por otras organizaciones de la sociedad civil que intervienen en la construcción institucional del organismo.

La ley prevé que el CPRES desarrolle objetivos de articulación entre niveles educativos, la detección de necesidades de educación superior a nivel regional posibles de atender por el marco institucional y la coordinación entre universidades (artículos 10, 71 y 72 de la Ley 24.521/95). El sistema de decisiones que origina estos objetivos se produce en instancias de poder central; es decir, el gobierno nacional, plasmado en el poder ejecutivo y el poder legislativo nacional -que en Argentina son poderes representativos-, no siempre cristaliza en intereses territoriales.

La obtención de dicho marco regulatorio expresó, por un lado, los intereses contenidos en la propuesta legislativa nacional de una posición más autonómica que, siguiendo lineamientos internacionales de ajuste presupuestario, buscó mejorar los problemas de calidad educativa desde posiciones que dieran más libertades a las universidades para la producción de recursos institucionales y financieros. Pero, además, representó los intereses de otra posición de carácter más regulacionista, donde tuvo la oportunidad de incorporar, desde una mirada técnica, los objetivos de planificación regional. En ese marco, la decisión de crear los CPRES estuvo impulsada por razones técnico-políticas que dan respuesta a las demandas internacionales de los noventa en contextos de restricción presupuestaria y a la necesidad de fortalecer la capacidad organizativa de "territorios" para el desarrollo de sistemas sociales, culturales y productivos locales. Se promueve así la configuración de una red de instituciones de educación, organismos de investigación y empresas conectadas con el tejido social e institucional de cada localidad o región.

La Ley de Educación Superior 24.521 de 1995 recupera para el CPRES el tipo de abordaje regional propuesto por el paradigma de planificación iniciado en los años sesenta. Pero en el transcurso de la 
implementación se observa que la trama de poder entre diferentes niveles de gobierno ha modificado las condiciones políticas e institucionales de origen, alterando su propósito descentralizador inicial (González, 2013; 2018). De 1996 a 2018 la actividad del CPRES da cuenta de grados de dinamismo disímiles por región y una tendencia al protagonismo del poder central para fijar una agenda de trabajo federal. El tratamiento de las actas de reunión plenaria de los organismos examinados evidencia que el mayor impulso a la actividad del CPRES tiene origen en intereses nacionales (González, 2013; 2018). Si bien el CPRES, como institución, ha logrado constituirse en un actor reconocido para la negociación y como una instancia influyente para la política universitaria, en los hechos se puede notar que su dinamismo está fuertemente vinculado a la participación de los poderes públicos y universitarios. La presencia o ausencia de las universidades de mayor tamaño y tradición y la participación de universidades agrupadas en consorcios se vuelve un aspecto clave para el avance institucional del CPRES.

Las relaciones en el interior del campo universitario suelen expresarse de modo competitivo entre los sectores público y privado, donde priman los sesgos en torno a los fines educativos de cada uno de ellos. Mientras que, por otro lado, se observa una mayor cooperación entre los poderes políticos situados en distintos niveles de gobierno y las universidades nacionales.

El gobierno nacional moviliza las agendas universitarias en función de su inserción en un conjunto más amplio de problemas derivado de la agenda internacional. Por su parte, las universidades nacionales tienen una incidencia relevante dado que su participación (o no) define la posibilidad de avanzar en políticas de concertación.

Por otro lado, la observación sobre los roles de los actores sociales y empresarios muestra que ocupan un lugar muy marginal en la construcción de la agenda regional (González, 2013; 2018).

Hasta aquí se ha relatado el proceso que orientó la conformación de un marco regulatorio para el esquema de descentralización del CPRES. En la discusión comparativa, se analizará el modelo de planificación que efectivamente funciona. El análisis del territorio metropolitano y bonaerense permite entrever que el CPRES atraviesa por distintos contextos y etapas históricas que determinan varia- 
ciones en su comportamiento como actor político gubernamental y marcan distintos grados de intervención pública.

En este marco, la investigación distingue la sucesión de tres periodos histórico-políticos. El primero se extiende de marzo de 1996 a diciembre de 1999; en un sentido amplio, se caracteriza por la consolidación de la estructura organizativa de la SPU, creada en 1993, y en particular por el desarrollo de un entramado de actores encargado de poner en marcha una agenda de trabajo para el CPRES. El segundo periodo se ubica entre diciembre de 1999 y principios de 2002; se caracteriza por el predominio de un contexto de restricción presupuestaria en el nivel nacional, y en particular, por la reformulación del diseño institucional que dio origen al CPRES. El tercer periodo -que llega hasta 2011- está determinado por los cambios de signo y conducción política en la Presidencia de la Nación, primero con Eduardo Duhalde (2002-2003) y luego con Néstor Kirchner (20032007); se caracteriza por una mayor intervención estatal en el funcionamiento del sistema de educación superior y por un incremento y fortalecimiento de las funciones ejecutivas que despliega el CPRES en relación con las actividades de tutela previas. Para los tres periodos se puede afirmar que tanto las condiciones de contexto como la intervención de otros actores han interpelado la figura del CPRES. Ambos factores impulsaron la intromisión progresiva del CPRES en la acción pública y dieron lugar a una mayor especificación de los roles y funciones puestos en marcha.

\section{El caso de Barcelona}

\section{Política y condiciones jurídicas institucionales}

Barcelona es la capital de Cataluña. La ciudad, que tiene la característica de estar abierta al mundo por su cultura y situación geográfica, ha protagonizado a lo largo de los siglos una gran actividad internacional como capital mediterránea y europea. Fundada por los romanos en el siglo I a. C. sobre antiguos asentamientos griegos y cartagineses con el nombre de Barcino, la situación estratégica de su puerto permitió a la urbe desarrollar una intensa actividad comercial 
desde sus orígenes. El periodo medieval fue la época de máximo desarrollo de esta actividad en todo el Mediterráneo. Bajo la protección del poder político del conde de Barcelona y de su Consejo de Ciento, la metrópoli articuló una extensa red de ciudades con las que mantenía intercambios comerciales, la cual recibía el nombre de Consulado de Mar.

La pérdida de autonomía política a raíz de la derrota de los catalanes durante la guerra de sucesión española no impidió que continuase desarrollando su actividad comercial y económica hacia el Atlántico. Así, durante el siglo XIX la ciudad mantuvo una intensa relación con Cuba y las Antillas, y tuvo un papel importante en el proceso de industrialización de España. Barcelona fue sede de dos exposiciones universales, en 1888 y en 1929, que dieron lugar al despertar político, social y cultural de la ciudad, abriendo la urbe al continente europeo.

En los años del gobierno progresista en España (entre 1852 y 1854), la actividad industrial empezaba a crecer en el país, y Barcelona aprobó el Plan Cerdà, un proyecto de reforma urbana que pretendía integrar en un mismo esquema circulatorio el ensanche (eixample), el puerto y la ciudad antigua.

La historia española del siglo XX, especialmente durante el periodo de la dictadura franquista, no posibilitaba que Barcelona desarrollara un modelo coherente de ciudad más allá del Plan Cerdà. Durante cuarenta años la urbe vivió inmersa en un clima de constante represión y censura que le impidió cualquier tipo de manifestación contraria al régimen.

Los tiempos de la guerra civil española y la dictadura de Franco dieron paso a la recuperación democrática de España y al reconocimiento de la autonomía política de la ciudad mediante la Constitución española de 1978 y el Estatuto de Autonomía de Cataluña de 1979.

El Estatuto de Autonomía de Cataluña consolidado en 2013 sigue el espíritu del Preámbulo del Estatuto de 1979, asumiendo que:

[...] el autogobierno de Cataluña se fundamenta en la Constitución, así como en los derechos históricos del pueblo catalán que en el marco de aquélla dan origen en este Estatuto al reconocimiento de una posición 
singular de la Generalitat. Cataluña quiere desarrollar su personalidad política en el marco de un Estado que reconoce y respeta la diversidad de identidades de los pueblos de España [...] La tradición cívica y asociativa de Cataluña ha subrayado siempre la importancia de la lengua y la cultura catalanas, de los derechos y los deberes, de la cohesión social, del desarrollo sostenible y la igualdad de derechos [...] [Parlament de Catalunya, 2013, p. 20].

Cataluña, en tanto nacionalidad, ejerce su autogobierno constituido como Comunidad Autónoma, de acuerdo con la Constitución y el Estatuto de 2013. En este marco, la Generalitat es el sistema institucional en el que se organiza políticamente el gobierno de Cataluña. La Generalitat está compuesta por el Parlamento, la Presidencia de la Generalitat, el Gobierno, y otras instituciones complementarias como: el Consejo de Garantías Estatutarias, el Síndico de Greuges (a cargo de la defensa de los derechos y libertades reconocidos en el Estatuto) y el Consejo Audiovisual de Cataluña (autoridad reguladora independiente en el ámbito de la comunicación audiovisual pública y privada).

La organización territorial local se estructura en municipios y veguerías. El ámbito supranacional está constituido por las comarcas, reguladas por una ley del Parlamento. Los demás entes supranacionales creados por la Generalitat se fundamentan en la voluntad de colaboración y asociación de los municipios.

El Estatuto consolidado de 2013 garantiza a los municipios un grupo de competencias propias ejercidas con plena autonomía, sujetas sólo a control de la legalidad y la constitucionalidad. Entre las competencias que ejercen se encuentran: a) la ordenación y gestión del territorio, el urbanismo y el cuidado de bienes de dominio público local; b) la planificación de la vivienda y la gestión del suelo; c) la ordenación y prestación de servicios básicos a la comunidad; d) la gestión, provisión y vigilancia de los espacios públicos y sociales, y el uso de los ámbitos privados.

La distribución de las responsabilidades administrativas entre los distintos gobiernos locales debe tener en cuenta su capacidad de gestión y se rige por las leyes aprobadas por el Parlamento, por el principio de subsidiariedad - de acuerdo con lo establecido por la Carta Europea de la Autonomía Local-, por el principio de diferen- 
ciación -con base en las características que presenta la realidad municipal-y por el principio de suficiencia financiera.

La Generalitat es la que determina los mecanismos para la financiación de los nuevos servicios derivados de la ampliación del espacio competencial de los gobiernos locales.

El Consejo de Gobiernos Locales es el órgano de representación de los municipios y veguerías en las instituciones de la Generalitat.

El municipio es el ente local básico de la organización territorial de Cataluña y el medio esencial de participación de la comunidad local.

El gobierno y la administración municipales corresponden al ayuntamiento, integrado por el alcalde o alcaldesa y los concejales. El Estatuto garantiza al municipio la autonomía para el ejercicio de las competencias asignadas y la defensa de los intereses propios de la colectividad que representan. Los actos y acuerdos adoptados por los municipios no pueden ser objeto de control de oportunidad por ninguna otra administración.

Por su parte, la veguería es el ámbito territorial específico para el ejercicio del gobierno intermunicipal de cooperación local y tiene personalidad jurídica propia. Es de naturaleza territorial y goza de autonomía para la gestión de sus intereses.

Los años setenta marcan para las economías capitalistas desarrolladas el final de un periodo de expansión económica, caracterizado por un conjunto de factores favorables que proporcionaron tasas de crecimiento equilibrado y situaciones de pleno empleo. En tales circunstancias, los gobiernos llevaron a cabo importantes programas de bienestar social sin comprometer por ello el proceso de acumulación capitalista, y se abrió un margen objetivo en el sistema que permitió el desarrollo de nuevos esquemas de gobierno local para atender las demandas socioeconómicas acuciantes. Con el brusco aumento del precio de los productos energéticos, factor desencadenante del ciclo recesivo, la lógica empresarial impuso la reducción de costos para mantener competitivos a los productos. Como consecuencia de ello, se generó una fase de destrucción masiva de empleo y, en general, de modificación de estructuras productivas. El proceso de cambio tecnológico se añadió como un factor decisivo en el cuadro general de transformaciones. 
La relación capital-trabajo sufrió una variación radical que incidió en las formas de relación social y en los modos de organizar la estructura política y gubernamental. Las políticas de los años ochenta fueron cuidadosas del gasto público y de la contención de los problemas sociales derivados de tales procesos.

A nivel agregado, estos cambios produjeron un impacto en los modos de concebir el espacio urbano. Por un lado, hubo un crecimiento de los intereses privados que avanzaron sobre la apropiación del entorno y el uso de los espacios públicos. Por otro, se desarrolló una multiplicación de espacios donde operaba la política que presiona a los gobiernos a institucionalizar instancias de concertación pública.

El espacio se empezó a concebir como una arena de conflicto donde se dirimen los intereses de capitales privados en torno a la construcción masiva de terrazas, pisos y centros comerciales que cercenan el uso público, mientras otros intereses comunitarios presionan las agendas de actuación gubernamental y son contrarios a dicha especulación.

Debido a la transformación en la estructura industrial y a la existencia de dichos intereses en pugna, se han producido nuevos diseños urbanos y formas de gobernar la ciudad.

La nueva economía posindustrial encierra una redistribución más desigual de la riqueza, manteniéndose índices de paro muy elevados tanto en zonas históricamente deprimidas como en regiones de industrialización clásica fuertemente castigadas por la crisis.

La ciudad se convirtió en el marco sociopolítico donde se manifiestan de forma más abierta las consecuencias de la nueva situación económica. La recesión incide con fuerza en las urbes, provocando el desmantelamiento de sectores enteros en crisis, y dejando tras de sí la secuela de un alto grado de descomposición de los tejidos industriales urbanos. La pérdida de puestos de trabajo adquiere especial relieve, y las consecuencias sociales del paro configuran la sociedad fragmentada y dual propia de extensos espacios suburbanos. Surge un volumen importante de economía sumergida.

Los nuevos planteamientos de desarrollo territorial, basados en un nivel tecnológico elevado y superadores en gran parte de las economías de aglomeración, arrojan los primeros datos positivos en 
cuanto al relanzamiento de la actividad económica (Subirats, 1987). Pero la superación del conjunto de problemas sociales, que definen una situación de crisis en el modelo urbano tradicional, empezó a requerir planteamientos nuevos de intervención municipal en materia de contención social y reactivación económica.

Ante las consecuencias negativas de la crisis, los primeros ayuntamientos democráticos empezaron a dirigir ciertos esfuerzos en el terreno económico y social. De este modo, los ayuntamientos comenzaron a gestionar una serie de competencias tradicionales de urbanismo, vivienda, obras públicas y educación, que pueden ser instrumentadas al servicio de los proyectos de reactivación económica de barrios y zonas urbanas desfavorecidas.

Barcelona se convirtió en una ciudad importante por tres razones: a) después de las elecciones de 1979 surgió un gran grupo de gestores con iniciativas y ambiciones que comenzaron a diseñar y desarrollar los planes estratégicos de ciudad; $b$ ) Barcelona, como Cataluña, es una urbe abierta al extranjero; y c) la sociedad civil catalana ha entendido que su fuerza depende en gran medida de la fuerza de Barcelona.

Desde esta época, se produce una temprana descentralización de la ciudad para atender a la organización de las demandas internas -de salud, educación y servicios públicos- y externas - tanto del territorio donde está situada, como en el ámbito continental.

\section{Políticas territoriales de fortalecimiento local e innovación pública}

El llamado "modelo Barcelona" de transformación urbana tiene una dimensión sustantiva, en tanto que es una estrategia determinada para lograr el cambio urbanístico, pero también posee una dimensión operativa, en tanto que es una fórmula específica de elaboración de políticas urbanas. Entre los elementos habitualmente atribuidos a este modelo, se acostumbra destacar como estrategias de transformación urbana a: la utilización de la cultura y de los grandes acontecimientos; la introducción de la lógica de la planificación estratégica; la cooperación entre distintos niveles de gobierno; las relaciones de 
partenariado entre los agentes públicos y privados; la descentralización política local; y el desarrollo de mecanismos de participación ciudadana (Ayuntamiento de Barcelona, 1999). A pesar de que los elementos apuntados en el esquema teórico de este artículo deberían poner en cuestión la originalidad de este modelo, como mínimo sí permiten constatar que la perspectiva de la gobernanza urbana ha tenido una clara proyección sobre esta ciudad.

Se parte de un diagnóstico que reconoce el carácter multidimensional de los problemas - que son graduales-en los diferentes barrios que componen a la ciudad y que perfilan formas de habitar específicas. Los procesos de descentralización urbana en Barcelona asumen la forma de empoderamiento local.

En particular, se destacan dos programas: uno de regeneración urbana y otro de innovación social. El liderazgo del primero ha recaído sobre los gobiernos locales, y se ha podido desarrollar gracias a una red de cooperación entre distintos niveles de gobierno. El Ayuntamiento de Barcelona -más concretamente, el Instituto Municipal de Urbanismo- ha liderado el diseño y la implementación de la regeneración del Raval y del conjunto del centro histórico. Sin embargo, otras administraciones han participado en el proceso: la Comisión Gestora del ARI, compuesta por representantes de las áreas de urbanismo del Ayuntamiento y de la Generalitat de Cataluña, además de los representantes de las asociaciones de vecinos de cada barrio del centro histórico; las administraciones central, autonómica y local cofinancian buena parte de las intervenciones de remodelación; la Unión Europea, a través de los Fondos Regionales, ha cofinanciado una de las operaciones de remodelación de mayor magnitud. Algunos de los proyectos han sido impulsados por el Plan Comunitario, como por ejemplo, la remodelación urbanística o el Proyecto Educativo de Barrios, que han contado con el apoyo de otras administraciones supralocales.

Los procesos de descentralización urbana han otorgado a los barrios capacidades de gestión pública e instancias institucionales de concertación. En este marco se han impulsado relaciones de cooperación entre actores públicos y privados. En las redes que impulsan estos programas de regeneración podemos identificar distintos niveles de la administración pública, diferentes departamentos, empre- 
sas públicas o de capital mixto, empresas privadas, universidades, profesionales independientes, asociaciones cívicas y ciudadanos a título individual. Es decir, en ambos casos se reconocen las limitaciones del enfoque burocrático de la elaboración de las políticas urbanas.

A su vez, se observa que la posibilidad de liderar los proyectos locales ha generado que cada barrio plasme objetivos diferentes y se base en prioridades de acción específicas, atento a la relevancia de la problemática en cada territorio. La demanda de cada espacio también forma parte del "llamado de atención" que los vecinos emiten para cada uno de los espacios públicos; aunque, en términos generales, las demandas se canalizan en cada una de las instancias municipales donde se provee un curso resolutivo en los plazos de tiempo fijados institucionalmente (Blanco, 2009).

Otro conjunto de políticas exitosas asociadas a los liderazgos locales está representado por nuevas prácticas de innovación pública. Esto ha implicado un triple giro conceptual, sustantivo y operativo, a saber: a) el impulso de nuevas formas de concebir los problemas colectivos; ya no se trata de situarlos en una matriz estado-céntrica, sino que se valora la producción de iniciativas que ocurren en la intersección entre la esfera institucional y la ciudadanía; b) la reorientación sustantiva de las acciones y los comportamientos de respuesta a los problemas y retos colectivos; y c) la inclusión de nuevos actores y la transformación de las relaciones políticas y sociales.

\section{Los actores}

Para dar cuenta de la manera en que suceden las relaciones de poder entre los diferentes niveles de poder y cómo se toman las decisiones, sirve examinar la forma en que se produce la creación de un instrumento de política pública que surge como respuesta a los problemas sociales complejos de la ciudad. Desde la interacción entre el Ayuntamiento de Barcelona con la Universidad Autónoma de Barcelona se creó un insumo para la gestión denominado Mapa de la Innovación Social. Específicamente, el Instituto de Estudios Regionales y Metropolitanos de Barcelona (IERMB) colabora con el 
Ayuntamiento en respuesta a la iniciativa oficial de hacerlo intervenir en las agendas de actuación del territorio metropolitano. Las agendas de actuación en el área metropolitana ya habían tomado dinamismo en forma previa, con demandas de las comunidades locales frente a los problemas sociales complejos de sus bases. Ante dichas iniciativas comunitarias, el Ayuntamiento creó la instancia de construcción de un mapa social -previamente inexistente- que incorpora la representación de los barrios, las autoridades locales y los investigadores expertos del campo universitario.

El mapa recoge diagnósticos sobre las problemáticas elementales de la ciudad (salud, educación, vivienda, empleo, etc.) y las formas en que los diferentes municipios les han dado respuesta. De ello surge una cartografía donde se observa la distribución territorial de las prácticas de innovación social en el área metropolitana de Barcelona. Atenta a ello, la comunidad académica de la universidad diseñó un estudio etnográfico con una muestra intencional de ocho municipios para indagar los factores explicativos de la emergencia de nuevas prácticas innovadoras, sus protagonistas y los entornos urbanos que facilitan su aparición. A partir de este trabajo, han presentado un conjunto de experiencias ejemplares de lo que se denomina innovación social. Es decir, prácticas sociales de cooperación horizontal que buscan satisfacer necesidades colectivas de signo diverso (acceso a espacios comunitarios, consumo de productos ecológicos, disponibilidad de créditos, acceso y gestión ciudadana de las telecomunicaciones, etc.). Tienen como particularidad la promoción de iniciativas alternativas a los modelos hegemónicos de consumo, producción y/o relación entre las personas y su entorno social y territorial. Estas iniciativas dan cuenta de la resignificación del espacio público como espacio social no dado o preconcebido, sino resultado de una construcción social.

Por un lado, están las iniciativas ligadas a fomentar un modelo alternativo en aspectos básicos del sistema socioeconómico, como son: el consumo alimentario, el acceso a la vivienda, el uso y gestión de los espacios públicos, el consumo energético, el trabajo, la salud y la educación (iniciativas proactivas). Por otra parte, se identifican otras iniciativas que tienen por objetivo principal combatir los impactos de la crisis y las políticas de austeridad, y defender los de- 
rechos sociales básicos, tales como la vivienda, la alimentación, el trabajo o la educación (iniciativas reactivas y reparadoras).

En el campo educativo, por ejemplo, la identificación de prácticas bajo el modelo alternativo ha puesto en marcha cooperativas de enseñanza, el movimiento de cultura libre, el arte comunitario y los comedores escolares ecológicos. Mientras que el modelo opuesto, el reparador, ha instalado grupos de ayuda mutua como práctica predominante.

Otras categorías y prácticas de innovación social operan en el campo del trabajo, la economía, el medio ambiente y el territorio, y la salud pública. En el campo del trabajo, el modelo proactivo ha implementado cooperativas de segundo grado; mientras, el modelo de innovación reactiva giró en torno a la defensa de derechos y la constitución de asambleas de desempleados y nuevos sindicalismos capaces de organizarlos.

\section{Cuadro 1}

Políticas proactivas y reactivas en el modelo Barcelona

\begin{tabular}{|c|c|c|}
\hline & \multicolumn{2}{|c|}{ Modelo } \\
\hline & $\begin{array}{c}\text { Alternativo } \\
\text { Políticas proactivas }\end{array}$ & $\begin{array}{c}\text { Contención o reparador } \\
\text { Políticas reactivas }\end{array}$ \\
\hline \multirow[t]{4}{*}{ Educación } & Cooperativas de enseñanza & Grupos de ayuda mutua \\
\hline & Movimientos de cultura libre & Cooperación pedagógica \\
\hline & Arte comunitario & Articulación entre instituciones \\
\hline & $\begin{array}{l}\text { Comedores escolares } \\
\text { ecológicos }\end{array}$ & \\
\hline \multirow[t]{3}{*}{ Trabajo } & Cooperativas de segundo grado & Defensa de derechos \\
\hline & & Asambleas de desempleados \\
\hline & & Nuevos sindicalismos \\
\hline \multirow[t]{2}{*}{$\begin{array}{l}\text { Derecho } \\
\text { a la ciudad }\end{array}$} & Granjas urbanas & $\begin{array}{l}\text { Prácticas de asociación } \\
\text { de intermediación }\end{array}$ \\
\hline & Cooperativas de viviendas & $\begin{array}{l}\text { Movimientos antisegregación } \\
\text { urbana }\end{array}$ \\
\hline
\end{tabular}

Fuente: Elaboración propia.

Otro de los ejes temáticos relevantes es el vinculado al derecho a la ciudad. Bajo el modelo alternativo proactivo se encuentran prác- 
ticas de granjas urbanas y cooperativas de viviendas; en tanto que, desde el modelo que combate los efectos de políticas de austeridad, se han implementado prácticas de asociación de intermediación y movimientos antidesahucio.

Un elemento transversal que revela el conjunto de áreas temáticas es el valor de la cooperación y la confianza en el poder comunitario para organizarse y gestionar respuestas colectivas a problemas individuales compartidos.

La agenda de actuación local en el modelo Barcelona tiene una fuerte dimensión participativa. Esto es más común, como se indicó, en áreas donde la población tiene mayor tamaño y recursos, como puede ser el eje centro-norte de la ciudad, donde además existe una orientación urbanística hegemónica. En zonas más periféricas, los programas y proyectos encuentran mayores dificultades de implementación debido a la incidencia de otros procesos, como la deposición (Borja, 2005; Gomá, 2018); esto ocurre en Ciutat Vella, Sant Andreu-Sagrera y Poble Nou-Front marítim-Besós, pues estas áreas están aún en proceso de transformación.

No es casual que precisamente en dichos territorios se haya producido tanto un renacimiento innovador del movimiento asociativo, como una efervescencia de debates más o menos críticos en el plano intelectual, profesional y político. El movimiento asociativo de base territorial no sólo ha implicado a las asociaciones de vecinos, también a otras entidades antiguas o de reciente creación, a colectivos informales y a ciudadanos que se han movilizado regularmente para realizar debates y acciones reivindicativas o de protesta.

Lo que a juicio de Borja (2005) llama especialmente la atención son dos aspectos: 1) la capacidad para construir plataformas o coordinadoras que reúnen a barrios contiguos que se enfrentan a la misma situación (y oportunidad) de cambio, así como la aparición de nuevos liderazgos; 2) la capacidad de construir un discurso crítico y propositivo que utiliza muchas veces con inteligencia los valores que orientaron y legitimaron el urbanismo barcelonés de la democracia para oponerse a algunos de los proyectos y actuaciones del presente. Este discurso crítico parece sustentarse en la crítica a la desposesión, o en la aspiración a la reapropiación del territorio, de su identidad y de su cohesión. 
El discurso sobre los derechos ciudadanos se hace más complejo, y la reivindicación vecinal inmediata y casi particularista se combina con el discurso sobre el proyecto de ciudad, casi de vida. Se asume la confrontación cívico-política, se pide diálogo y concertación a las administraciones públicas, se denuncia la arrogancia del poder, se recupera y se desarrolla el discurso participativo. Este renacimiento asociativo encuentra apoyo y legitimación en la progresiva crítica intelectual y profesional a algunos de los proyectos urbanos más significativos de la última década, a su concepción en unos casos y a su implementación en otros; aunque la importancia de los encargos públicos limita considerablemente la capacidad crítica de los profesionales más relevantes o conocidos. En Ciutat Vella, el centro histórico de Barcelona, ha prevalecido una crítica más ideológica y minoritaria, denunciadora de una "gentrificación" relativamente modesta y de algunos proyectos considerados "especulativos", mientras que la población se preocupa de problemáticas más inmediatas y acuciantes sobre la vivienda, la pobreza, la limpieza y la seguridad en el espacio público, y la convivencia entre poblaciones distintas.

Más allá de estos retos, el modelo Barcelona parece haber construido un régimen autonómico de bienestar con dinámicas de expansión y consolidación en ejes temáticos que involucran a los derechos sociales básicos ya mencionados.

\section{Encuentros y desencuentros entre experiencias metropolitanas}

Las experiencias examinadas en las dos ciudades bajo análisis permiten entrever semejanzas y diferencias que vale la pena destacar.

Se observa que tienen en común marcos normativos semejantes, una multiplicidad de espacios donde opera la política y nuevas condiciones de contexto que interpelan la acción de los gobiernos centrales.

Una variable que interviene fuertemente en ambas ciudades es la vinculada a la emergencia de una multiplicidad de intereses territoriales que contribuyen a modelar la política desde perspectivas que contemplen la diversidad.

Un segundo elemento común es el entramado relacional entre distintos tipos de actores con diferentes estrategias y grados de poder. 
Se identifican poderes centrales y otros periféricos, detectándose dentro de estos últimos algunas periferias más significativas que otras.

La tercera variable que interviene en la construcción política y social que movilizan los actores tiene que ver con nuevas condiciones de contexto muy ligadas a la influencia internacional de corrientes hegemónicas sobre gobernanza metropolitana. La gobernanza avanza como un modelo isomórfico de carácter abstracto, universal y perfectamente aplicable a cualquier ciudad. A partir de ello, y en función de la redefinición de la matriz estado-céntrica y la creación de nuevos actores territoriales, se adopta como un paradigma superador de aquellos que plantean que el gobierno se direcciona desde abajo (la sociedad), modelo bottom-up, o bien desde arriba (desde las políticas estatales), modelo top-down. Sin embargo, la fijación de paradigmas universales no siempre se traduce en políticas concretas. El análisis de los casos de Barcelona y Buenos Aires evidencia que su internalización (o no) está estrechamente asociada al modo en que se distribuyen la capacidad y el poder político entre los actores dominantes y los periféricos, así como también a la cultura organizacional de cada una de las ciudades bajo análisis.

Las diferencias entre ambas ciudades surgen precisamente en las condiciones de implementación, lo que da lugar a la configuración de dos modelos de ciudad. Es el interés por la arena política lo que moviliza a los actores. En ambos casos se puede notar que, desde el punto de vista jurídico normativo, los actores tienen habilitadas instancias legales de participación. Aunque, en los hechos, no todos los actores gozan de igual capacidad de negociación e influencia en la arena política, sea por sus ausencias o por la debilidad de sus estrategias e intervenciones. Los actores tienen grados variables de poder y pueden constituirse como actores políticos cuando tienen capacidad de influencia y legitiman sus agendas de actuación. Esta variable muestra dinámicas divergentes en cada ciudad.

\section{La experiencia de transformación en Buenos Aires}

Para el caso de Buenos Aires, los diseños institucionales se crean desde el poder nacional (leyes) para reforzar las atribuciones jurí- 
dico-normativas de las regiones educativas y las provincias que las componen. Como se mencionó previamente, la ley crea siete regiones CPRES. Cada región se compone de un número diverso de provincias. Un dato distintivo resulta del examen de las regiones CPRES Bonaerense y Metropolitana. El CPRES Bonaerense se compone de una sola jurisdicción provincial (la Provincia de Buenos Aires, excepto los 24 partidos del Conurbano Bonaerense). Esta provincia registra un movimiento educativo relativo en relación al resto de las regiones. El CPRES Metropolitano, en cambio, reúne a dos jurisdicciones provinciales (la Ciudad Autónoma de Buenos Aires y los 24 partidos que integran el Conurbano Bonaerense). Además, en este CPRES se encuentra la universidad de mayor tamaño y tradición (la Universidad de Buenos Aires) y un movimiento potente de universidades de nueva generación en el Conurbano Bonaerense.

Las regiones CPRES Bonaerense y Metropolitana son las que, durante los últimos veinte años, han mostrado mayor evolución respecto de las actividades de regulación y planificación que la ley les ha asignado. En estas regiones, la participación de las autoridades nacionales y de las universidades de mayor tamaño y tradición han marcado dinámicas de mejor calidad institucional, en comparación con el resto de las regiones. A ello se suma que en estas regiones las empresas y otros actores sociales inciden activamente como actores periféricos significativos.

En la región CPRES del área metropolitana se observa una pluralidad de actores e instituciones que ha derivado en la búsqueda de respuestas colectivas para la producción de nuevas concertaciones públicas. Un buen ejemplo de ello lo constituye la red universitaria denominada Red de Universidades Nacionales del Conurbano Bonaerense (Runcob). Esta red es producto de la asociación de universidades nacionales del Conurbano Bonaerense, creadas entre los años noventa y la actualidad, para negociar con la Universidad de Buenos Aires (UBA) en condiciones de poder equivalente. Esta asociación permitió nuclear la defensa de los intereses colectivos y avanzar en el debate con la UBA, pues cada una de las universidades que conforman dicha red no lograba individualmente plasmar estrategias efectivas o ganar influencia en la misma región donde se encuentra la UBA. 
El CPRES Bonaerense, en cambio, ha actuado de un modo "restrictivo", protegiendo o cercando el territorio ante el ingreso de otras instituciones que pudieran disputarle influencia a las universidades de origen. Así, se fue concentrando el sistema de decisiones en pocas instituciones universitarias, las cuales adquirieron una influencia central para la región.

En una investigación previa se determinó que, para el caso del CPRES, la ley crea instituciones que prevé actúen bajo un modelo de gobernanza urbana, aunque su creación responde al modelo topdown de política pública, donde es la autoridad central la que define el tipo de política. Además, en este caso se agrega que esta creación se dio sin una transferencia adecuada de recursos físicos y financieros. Así, quedó librado a la voluntad y valorización del espacio por parte de los actores de cada región en cuanto a la forma de implementar las políticas en el nivel local (González, 2013).

Cada una de las cinco regiones CPRES restantes se integra por un número mayor de provincias (entre cuatro y seis, aproximadamente) y cerca de cuatro universidades nacionales por cada región. Las provincias están representadas en cada Consejo por las autoridades de cada una de las jurisdicciones subnacionales. Si bien estas regiones se componen de una mayor cantidad de instituciones con poder equivalente, esto no ha repercutido en una influencia positiva en términos de poder y construcción institucional, lo que en muchos casos puede evidenciar una cooptación de poderes relativos en el poder provincial como actor central (González, 2013).

\section{La experiencia de transformación en Barcelona}

En Barcelona se produce un movimiento inverso. Las instituciones públicas modifican la matriz normativa de las decisiones públicas $\mathrm{y}$, además de las instancias normativas, se instalan rutinas y prácticas sociales con múltiples espacios destinados a la deliberación colectiva. El Mapa Social de Innovación intenta mostrar de qué manera cooperan los actores para dar respuesta a las problemáticas sociales complejas. Para el diseño de dicho mapa se articulan los actores del poder central, que toman la iniciativa de construirlo, con los actores 
territoriales y universitarios. Los actores territoriales son los diferentes municipios, que exponen sus problemáticas en diversos espacios sociales donde asisten referentes universitarios preocupados por indagar y resolver cuestiones sociales acuciantes. Si bien cada sector se caracteriza por la defensa de sus intereses específicos, en todos los casos el objetivo común es la defensa del interés general asociado al bienestar de la mayor parte de la población de Cataluña. En ese sentido, la construcción de un mapa social con diagnósticos por área y soluciones innovadoras para los problemas presentados constituye un esfuerzo colectivo de intercambio y deliberación entre los actores de diferentes niveles territoriales.

El incremento de las problemáticas de carácter socioeconómico (desempleo, pobreza y otras formas de exclusión) coincide con el reconocimiento de la disminución drástica de las capacidades del sector público para afrontar este tipo de necesidades. Así, la innovación pública se presenta como una respuesta necesaria a esta tensión entre las necesidades sociales en aumento y las capacidades institucionales en retroceso (Cruz y Blanco, 2018). La innovación pública comienza a suponer la obtención de soluciones que pueden construirse desde la comunidad, a partir de la confrontación y el intercambio de visiones por parte de una gran pluralidad de actores situados en diferentes escalas territoriales. Por esta razón, tanto la innovación política como la social allí implicadas podrían ser interpretadas como un reflejo del intento de construir soluciones complejas para los problemas complejos (Rhodes, 1997, en Cruz y Blanco, 2018).

Los datos recolectados conducen a pensar que en Barcelona -a diferencia de la planificación territorial desde el estado central, visible en el caso de Buenos Aires-, la innovación pública se produce a partir de la presión comunitaria, de la demanda e influencia que ejercen las acciones sociales sobre las instituciones públicas. Se evidencia que la emergencia de prácticas sociales innovadoras actúa como un factor estimulador de prácticas similares en otros territorios y comunidades. La constitución de redes y plataformas de segundo nivel favorece estos procesos de reescalamiento y expansión territorial. De forma similar, las innovaciones en el sector público se expanden territorialmente gracias a la tarea de los gobiernos supramunicipales, o bien, como resultado del contagio de los relatos señalados como 
exitosos, que en algunos casos están acompañados de la construcción de redes interinstitucionales que favorecen la difusión de las mismas. Desde este punto de vista, cabe preguntarse en qué medida y en qué sentido la dispar distribución espacial de los procesos de innovación refleja desiguales capacidades territoriales para la innovación.

En suma, en Buenos Aires es el interés de los actores por la arena política en la que se desenvuelven -antes que la creación institucional en sí misma- lo que determina la eficacia de los objetivos políticos por región (González, 2013). Mientras que, en Barcelona, las mayores posibilidades de éxito están asociadas a la renta y al tamaño poblacional de los municipios. Estos factores pueden condicionar o facilitar la innovación pública. En este sentido, los municipios más grandes y con mayor renta podrían, a priori, estar más predispuestos a desarrollar procesos de innovación, mientras que los de menores dimensiones y menor renta podrían encontrar más dificultades. Aunque son estos últimos los que mayores incentivos tienen para la innovación social, política y pública debido a que las necesidades sociales son más intensas. Los incentivos a la innovación son, a priori, menores en los municipios de rentas más altas, pero la potencia de sus estructuras administrativas (sobre todo en los municipios grandes y medianos) puede facilitar que se produzca la innovación política, de la misma manera que entre los segmentos de renta mediana de estos municipios se puede prever una alta capacidad de innovación social, que en último término es reforzada mutuamente con las dinámicas de innovación de la administración municipal (Cruz y Blanco, 2018).

\section{Conclusiones}

Desde los años noventa, el contexto global que atraviesa el examen de las ciudades analizadas se caracteriza por el desarrollo de un doble proceso compuesto por la globalización y la evolución del neoliberalismo. Aunque el modo de enfrentar estos procesos ha sido diferente en cada urbe.

Más allá de la mayor autonomía formal de las instancias institucionales locales y subnacionales, la literatura al respecto destaca que 
su capacidad se encuentra generalmente limitada tanto por el tamaño de los espacios urbanos como por la escasez de recursos financieros que controlan, lo cual históricamente las ha llevado a concentrarse en funciones básicas. Sin embargo, las últimas dos décadas son testigo de una mayor intromisión de las ciudades en asuntos globales. Las metrópolis se han abierto al mundo, participando en foros internacionales, promoviendo en sus territorios congresos, ferias, foros, seminarios de carácter internacional, etc. Muchas urbes han logrado relacionarse entre ellas. La búsqueda de influencia en lo internacional ha sido realizada haciendo lobby frente a los organismos internacionales o regionales, creando organizaciones y redes internacionales de ciudades, a fin de aumentar su poder de persuasión y ampliar la esfera geográfica de sus demandas (Marx, 2008).

En el caso de Buenos Aires, la descentralización urbana tiene como punto de partida al gobierno central, haciendo que los poderes periféricos y subnacionales queden con menor capacidad de influencia en su constitución. En los hechos, esto se transmuta en una desigual capacidad de ejecución política entre los actores provinciales y los municipales. En Barcelona, en cambio, las políticas locales han escalado hasta influir en el gobierno central, en la Generalitat. Esto ha dado lugar a un mayor involucramiento e influencia política de los actores que gozan de poderes más o menos equivalentes.

La implementación de modelos isomórficos de gobernanza ha dado lugar a rendimientos heterogéneos según las ciudades. En Buenos Aires, esto dio lugar al diseño de modelos de asociación y redes de actores conformados en Consejos de Planificación de la Educación Superior, pero no se tuvieron en cuenta las condiciones de implementación; es decir, qué capacidad institucional dotaba a cada uno de sus actores centrales y qué capacidades técnicas y políticas detentan sus actores periféricos. En Barcelona, las condiciones de implementación fueron diferentes: los niveles territoriales y municipales se caracterizaban por el alto grado de incidencia en otros niveles superiores de poder; en este sentido, han sido las instancias sociales y políticas de participación local lo que ha dado lugar a la incidencia de la política central en los modelos de redes de política.

Desde un punto de vista jurídico más general, la Argentina actual se caracteriza por un federalismo de concentración que hace que 
las facultades concurrentes terminen siendo ejercidas en forma exclusiva por la nación, a la manera de un federalismo por desplazamiento, dejando a las provincias solamente potestades remanentes. La reforma de 1994 ha colocado en mejor situación a las provincias, al reconocerles la potestad de ejercer el poder de policía en los establecimientos de utilidad nacional, así como la de cobrar sus impuestos en dicho ámbito, mientras no se afectare su finalidad (art. 75 , inc. 30). Uno de los problemas graves de Argentina ha sido, y es, el de la fragilidad de sus instituciones y la falta de autonomía relativa de los distintos espacios institucionales (de la ciencia, la cultura, la universidad, la justicia, etc.). Dicha fragilidad se transmuta también en debilidad de los actores y en precariedad en la asunción de roles, responsabilidades y orientación normativa de las prácticas sociales.

En la ciudad de Barcelona, y en España en general, se observa que las instituciones públicas habilitan iniciativas locales para interpelar a las políticas más generales del gobierno central. Es precisamente el involucramiento político y comunitario a partir de estas instancias lo que permite movilizar las capacidades institucionales de carácter local y urbano.

El análisis propuesto permite constatar la existencia de ciertos elementos de crisis en las formas tradicionales de gobierno, y la emergencia, en su lugar, de principios innovadores propios de lo que, en la literatura, se ha denominado gobernanza local y urbana. En ambos casos, la complejidad de los problemas relacionados con la exclusión socioespacial parece haber presionado las formas de articular las políticas públicas hacia el cambio. Los actores involucrados reconocen los retos planteados por un entorno socioeconómico que ha experimentado grandes transformaciones en las últimas décadas, y que el impulso efectivo de las estrategias de regeneración urbana sólo puede producirse a partir de un replanteamiento en profundidad de las formas de trabajar en el territorio: desde el tratamiento homogeneizador de los problemas urbanos, hacia el reconocimiento de sus particularidades territoriales; desde los enfoques reactivos y asistencialistas, hacia los planteamientos que manifiestan vocación estratégica de transformación; desde los esquemas centralistas clásicos, hacia un nuevo escenario de liderazgo local de redes de gobernanza multinivel; desde la segmentación de responsabilidades entre 
los actores, hacia nuevas lógicas de reconocimiento de las interdependencias y la corresponsabilidad. Todos estos vectores de cambio se reflejan en ambas políticas y coinciden, en este sentido, con lo que en la literatura se ha denominado el paradigma de la gobernanza urbana, el mismo que en la ciudad de Barcelona ha permitido impulsar proyectos de gran escala, como el de los Juegos Olímpicos de 1992, la regeneración del conjunto del centro histórico o el Foro de las Culturas de 2004, con todas las transformaciones urbanas que cada uno de ellos ha logrado catalizar. O en el caso de Buenos Aires, el mismo modelo que ha dado lugar a la creación de planes de regionalización universitaria articulados entre provincias y actores de la comunidad local.

La comparación también nos ha permitido constatar la diversidad de trayectorias de cambio político en diferentes ciudades. Las políticas de descentralización, a pesar de responder ambas al paradigma de la gobernanza, difieren significativamente en algunos aspectos básicos: a) las asimetrías de recursos físicos y financieros; b) las desiguales capacidades para movilizar los recursos de poder; y c) las variaciones en el grado de interés por la arena política.

La valoración por el territorio es mayor en el caso de Barcelona, donde los actores asumen responsabilidad frente a la oportunidad de construir nuevas prácticas de gobierno desde lo social y lo político (Cuadro 2).

Como señala Jordi Borja (2005, p. 17), "la ciudad es un lugar privilegiado para la innovación democrática". La crisis del estado-nación, el agotamiento o la insuficiencia de la democracia representativa articulada únicamente por elecciones y partidos, y la falta de mecanismos que establezcan lazos entre lo local y lo global, significan hoy un reto de carácter mundial que tienen ante sí las ciudades y los gobiernos locales. Para responder a este reto es necesario reconstruir la urbe como actor complejo: combinar agentes públicos y privados con capacidad para actuar en la escena internacional y organizar a la sociedad sobre la base del principio político legitimador de la proximidad. En igual sentido, las ventajas sociopolíticas que aporta a las ciudades la proximidad a los problemas y la posibilidad de construir relaciones internas e internacionales desde la micropolítica local permiten pensar que en la actualidad las ciudades representan 
la idea de Estado tradicional. Hoy el Estado se visualiza en las ciudades. Por este motivo, un tema relevante a profundizar que puede derivarse de este análisis es la identidad y dinámica de los "localismos". Otro asunto que puede derivarse de este tratamiento está vinculado a la emergencia de nuevas agendas de actuación local en el marco más general de la profundización de los problemas globales y los procesos sociopolíticos que exceden las fronteras de los países, como pueden ser el desplazamiento de poblaciones desde áreas en conflicto, la segregación urbana, el cambio climático y las crisis energéticas.

\section{Cuadro 2}

Comparativo de variables comunes y divergentes para Buenos Aires y Barcelona

\begin{tabular}{lll}
\hline \multicolumn{1}{c}{ Buenos Aires } & \multicolumn{1}{c}{ Barcelona } \\
\hline Diferencias & $\begin{array}{l}\text { Distribución desigual } \\
\text { del poder político }\end{array}$ & Distribución equivalente de poder \\
& $\begin{array}{l}\text { Escasa incidencia } \\
\text { de los gobiernos locales }\end{array}$ & $\begin{array}{l}\text { Alta incidencia } \\
\text { de los gobiernos locales }\end{array}$ \\
& Baja autonomía real & Alta autonomía municipal \\
& Cooptación & Cooperación \\
& Governance de baja calidad & Governance de alta calidad insti- \\
institucional & tucional \\
\hline Semejanzas & Nuevas condiciones de contexto que desafían los equilibrios de \\
& poder constituidos. & \\
& Influencia de modelos hegemónicos sobre gobernanza urbana. \\
& Nuevos actores regionales. \\
& Multiplicación de espacios donde opera la política. \\
& El espacio es una construcción social. \\
\hline
\end{tabular}

Fuente: Elaboración propia.

\section{Bibliografía}

Ayuntamiento de Barcelona. (1999). Arxiu Municipal Contemporani deBarcelona. Página oficial del Ayuntamiento de Barcelona. https: //ajuntament.barcelona.cat/arxiumunicipal/arxiucontemporani/ es/archivo-contemporaneo 
Blanco, I. (2009). Gobernanza urbana y políticas de regeneración: el caso de Barcelona. Revista Española de Ciencia Política, 20(4), 152-172. https://recyt.fecyt.es/index.php/recp/article/view/ 37478

Borja, J. (2005). Un futuro urbano con un corazón antiguo. Geograficando, Revista de Estudios Geográficos, 1(1), 1-13. https: //www.geograficando.fahce.unlp.edu.ar/article/view/GEO $\mathrm{v} 01 \mathrm{n} 01 \mathrm{a} 01 /$ pdf 96

Brenner, N. (2017). Teoría urbana crítica y politicas de escala. Barcelona: Icaria.

Brugué, Q. (2002). Nuevos ayuntamientos, concejales diferentes: del gobierno de las instituciones al gobierno de las redes. Revista Española de Ciencia Política, 7, 9-37. https://recyt.fecyt.es/ index.php/recp/article/view/37333

Brugué, Q. y Gomà, R. (2006). Bienestar y territorio. En A. Tarroja y R. Camagni (eds.), Una nueva cultura del territorio. Barcelona: CUIMPB.

Cruz, H. y Blanco, I. (2018). La innovación social y política: un análisis territorial en el área metropolitana de Barcelona. En El derecho a la metrópolis, Anuario.

Dalton, R. J. (2004). Democratic challenges, democratic choices: The erosion of political support in advanced industrial democracies. Reino Unido: Oxford University Press.

Denters, B. y Lawrence, R. (2005). Comparing local governance. Trends and developments. Nueva York: Palgrave.

Gomá, R. (2018). La metrópolis entre la gentrificación y el derecho a la ciudad. Revista Papers, 60, 11-14. https://iermb.uab.cat/es/ revistapapers/n-60-gentrificacion-y-derecho-a-la-ciudad/

Gomá, R. y Subirats, J. (1988). Nuevos escenarios de integración de intereses: los consejos económicos y sociales locales. Revista Española de Investigaciones Sociológicas, 44, 79-94. http:// www.reis.cis.es/REIS/PDF/REIS_044_06.pdf

González, G. (2013). El gobierno territorial de la educación superior. El rol del Consejo de Planificación Regional en el área metropolitana y bonaerense (1996-2011). Tesis de doctorado en Educación. Buenos Aires: Universidad de San Andrés. 
Grau-Solés, M., Iñiguez-Rueda, L. y Subirats, J. (2011). ¿Cómo gobernar la complejidad? Invitación a una gobernanza híbrida y urbana. Athenea Digital, Revista de Pensamiento e Investigación Social, 11(1), 63-84. https://atheneadigital.net/article/view/ v11-n1-grau-iniguez-subirats/827-pdf-es

Harding, A. (1995). Elite theory and growth machines. En D. Judge, G. Stoker y H. Wolman (eds.), Theories of urban politics (pp. 35-53). Londres: SAGE.

Lefebvre, H. (2013). La producción del espacio. Madrid: Capitán Swing.

Lowndes, V. (2005). Something old, something new, something borrowed. How institutions change (and stay the same) in local governance. Journal Policy Studies, 26(3-4), 291-309. https:// www.tandfonline.com/doi/abs/10.1080/01442870500198361

Marx, V. (2008). Las ciudades como actores politicos en las relaciones internacionales. (Tesis de doctorado, Universidad Autónoma de Barcelona, Facultad de Ciencias Políticas y Sociología). https://dd.uab.cat/pub/tesis/2009/tdx-0401109-152638/vm1 de1.pdf

Newman, J. (2005). Participative governance and the remaking of the public sphere. En J. Newman (ed.), Remaking governance: Peoples, politics and the public sphere (pp. 119-138). Bristol: The Policy Press.

Parlamento de Catalunya. (2013). Estatuto de Autonomía de Cataluña. Barcelona: Parlamento de Cataluña.

Stoker, G. (2004). Transforming local governance. Nueva York: Palgrave.

Stone, C. (1989). Regime politics: Governing Atlanta, 1946-1988. University Press of Kansas.

Subirats, J. (1987). Iniciatives Economiques Locáis i Concertado Social. Ajuntament de Barcelona, mimeo., 4 vols.

Subirats, J. (2016). El poder de lo próximo: las virtudes del municipalismo. Madrid: Catarata.

Subirats, J., Brugué, Q. y Gomà, R. (eds.). (2002). Redes, territorio y gobierno. Nuevas respuestas locales ante los retos de la globalización. Barcelona: Diputación de Barcelona. 


\section{Fuentes normativas}

Constitución de la Nación Argentina, Congreso de la Nación.

Ley de Educación Superior 24.521, Congreso Nacional de la Nación Argentina, 1995.

Decreto 499, Poder Ejecutivo de la Nación Argentina, 1995.

Decreto 576, Poder Ejecutivo de la Nación Argentina, 1996.

Decreto 1047, Poder Ejecutivo de la Nación Argentina, 1999.

Resolución Ministerio de Educación de la Nación Argentina 602/95, 1995.

Resolución Ministerio de Educación de la Nación Argentina 200/96, 1996.

Resolución Ministerio de Educación de la Nación Argentina 1671/06, 2006.

Resolución Ministerio de Educación de la Nación Argentina 1180/07, 2007.

\section{Acerca de la autora}

Giselle González es doctora, maestra y especialista en Educación por la Universidad de San Andrés. Es licenciada en Ciencia Política por la Universidad de Buenos Aires (UBA). Actualmente es docente de la UBA e investigadora en el Instituto de Investigaciones en Humanidades y Ciencias Sociales de la Universidad Nacional de La Plata y el Consejo Nacional de Investigaciones Científicas y Técnicas (Conicet). Su tesis doctoral fue premiada por Presidencia de la Nación y PNUD por su contribución a la innovación y al mejoramiento de las políticas públicas. Recientemente realizó una estancia postdoctoral en el Instituto de Gobierno y Políticas de la Universidad Autónoma de Barcelona, en el marco del Programa de Becas Externas de Conicet. Entre sus líneas de investigación se ubican los temas vinculados a: implementación de políticas públicas y educativas; federalización y distribución territorial; cambio institucional y dinámicas espaciales en áreas metropolitanas. Anteriormente realizó tareas de docencia e investigación en la Universidad de San Andrés y en el Ministerio de Educación de la Nación. ORCID: https://orcid.org/0000-0001-5818-0735 
Entre sus publicaciones se encuentran:

González, G. y Claverie, J. A. (2017). Planeamiento de la educación superior en Argentina: entre las políticas de regionalización y los procesos de innovación universitaria (1995-2015). Education Policy Review, 25, 1-36. https://www.redalyc.org/ pdf/2750/275050047112.pdf

González, G. (2011). La territorialización de las políticas públicas en Argentina. Un estudio acerca del Consejo de Planificación Regional de Educación Superior en el área metropolitana. Revista Iberoamericana de Educación Superior, 2(4), 41-61. http:// www.scielo.org.mx/pdf/ries/v2n4/v2n4a3.pdf

Recepción: 22 de agosto de 2019. Aceptación: 19 de marzo de 2020 
